\title{
Severity and Outcomes of Neurologic Deficits Associated with Pyogenic Spondylodiscitis: A Systematic Review
}

\author{
Naveed Nabizadeh, $M D^{1 *}$, Charles H Crawford III, MD ${ }^{1,2}$, Steven D Glassman, $M D^{1,2}$, John R Dimar, \\ $M D^{1,2}$ and Leah Y Carreon, $M D^{1,2}$
}

${ }^{1}$ Norton Leatherman Spine Center, Louisville, KY, USA

${ }^{2}$ Department of Orthopaedic Surgery, University of Louisville School of Medicine, $K Y$, USA

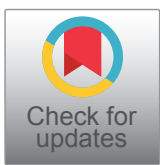

*Corresponding author: Naveed Nabizadeh, Norton Leatherman Spine Center, 210 East Gray Street, Suite 900, Louisville, KY, 40202, USA

\begin{abstract}
Introduction: Patients with advanced pyogenic spondylodiscitis can present with neurologic deficits, however, the prevalence, severity, and outcome of the neurologic deficits are not well known. A systematic review was performed to improve knowledge of this commonly encountered clinical scenario.

Methods: A comprehensive search of databases including PubMed, Science Direct and Google Scholar from 20002020 was performed. From 1478 articles, 75 were screened and 40 included. As the most commonly used classification for neurologic status was Frankel grading, we categorized the various neurologic findings corresponding to Frankel's descriptions. Results of treatment were expressed as complete recovery, partial recovery, unchanged, or deterioration.

Results: Among 3197 patients with pyogenic spondylodiscitis, 1314 cases showed a variety of neurologic manifestation: $415(32 \%)$ presented with subjective symptoms including radicular pain, sciatica or numbness, $899(28 \%)$ were diagnosed with a significant neurologic deficit on initial presentation. Patients with Frankel A/B deficits $(\mathrm{N}=286$, $22 \%$ ) had the lowest proportion with complete recovery $(16 \%)$ and the highest proportion to remain unchanged after treatment $(34 \%)$. Patients with Frankel $\mathrm{C}$ deficits $(\mathrm{N}=333$, $25 \%)$ were more likely to have complete recovery (29\%), although the majority had only partial recovery $(53 \%)$, or remained unchanged (16\%). Patients with Frankel $D$ deficits $(\mathrm{N}=280,21 \%)$ were the most likely to experience complete recovery $(53 \%)$ with a similar number of patients exhibited partial $(25 \%)$ or no recovery $(20 \%)$. A small percentage $(2 \%)$ of patients in each Frankel group deteriorated after treatment. The comparison of neurologic outcome in the
\end{abstract}

non-surgically treated ( $\mathrm{n}=97$ ) versus surgically treated ( $\mathrm{n}$ $=449$ ) patients revealed that surgical intervention was associated with improved neurologic recovery $(R=-0.205, p$ $<0.000$ ).

Conclusion: The considerable number of neurologic deficits in addition to their poor recovery even after surgical intervention demonstrates that early diagnosis of pyogenic spondylodiscitis is crucial. Prompt surgical intervention is likely associated with improved neurologic recovery when compared to non-surgical treatment.

\section{Keywords}

Osteodiscitis, Spondylodiscitis, Neurologic impairment, Neurologic deficit

\section{Introduction}

Spondylodiscitis is the most common form of hematogenous osteomyelitis in patients aged $>50$ years and represents $3 \%-5 \%$ of all cases of osteomyelitis [1]. Recently, the incidence of vertebral osteomyelitis has increased because of improved accuracy of diagnosis in addition to the rise in susceptible patients including diabetes mellitius, intravenous drug users, patients undergoing hemodialysis, and immune compromised hosts [2].

Neurological symptoms associated with spondylodiscitis have been reported with varying incidence, ranging from dysesthesia and radicular pain to complete paraplegia [3]. Previous studies have shown that neurological deficit $s$ develop because of epidural

Citation: Nabizadeh N, Charles HCIII, MD1,2, , Glassman SD, Dimar JR, Carreon LY (2021) Severity and Outcomes of Neurologic Deficits Associated with Pyogenic Spondylodiscitis: A Systematic Review. Clin Arch Bone Joint Dis 4:014. doi.org/10.23937/2643-4091/1710014 Accepted: September 04, 2021: Published: September 06, 2021

Copyright: (c) 2021 Nabizadeh N, et al. This is an open-access article distributed under the terms of the Creative Commons Attribution License, which permits unrestricted use, distribution, and reproduction in any medium, provided the original author and source are credited. 
abscesses or a pathological fracture. Furthermore, the severity of neurologic symptoms is correlated with delayed diagnosis, older age, virulence of the offending organism, and presence of co-morbidity. The purpose of this study is to report on the severity of neurologic impairment in spondylodiscitis patients and identify factors associated prognosis and neurologic recovery.

\section{Methods}

A comprehensive search of different databases including PubMed, MEDLINE, Science Direct and Google Scholar from 2000 to 2020, was performed. The searched keywords included "Vertebral Osteomyelitis" OR "Osteodiscitis" OR "Pyogenic Spondylodiscitis" AND "Neurologic Impairment" or "Neurologic Deficit". Manual search of reference lists from relevant papers and guidelines was performed.

Initially 1478 articles were collected and their abstracts were screened. Seventy-five articles were selected based on inclusion and exclusion criteria. After comprehensive review of full texts, 40 studies which contained detailed neurologic exams and were eligible for systematic review (Table 1).

Table 1: Contributing studies.

\begin{tabular}{|c|c|c|c|c|c|c|}
\hline Study & Sample size & $\begin{array}{l}\text { Age, year, } \\
\text { mean (SD) }\end{array}$ & Male, $\mathbf{N}$ & Multi-level, N & $\begin{array}{l}\text { Delayed } \\
\text { treatment, } \\
\text { days, mean (SD) }\end{array}$ & $\begin{array}{l}\text { Epidural } \\
\text { abscess, } \mathbf{N}\end{array}$ \\
\hline Asamoto [4] & 27 & 56 & 15 & 2 & - & 17 \\
\hline Ascione [5] & 30 & 64 & 13 & 0 & 48 & - \\
\hline Bernard [6] & 359 & 61 & 250 & 39 & 34 & - \\
\hline Bettini [7] & 56 & 47.8 & 21 & 6 & 50 & 3 \\
\hline Cervan [8] & 23 & 67 & 15 & 2 & 49 & 14 \\
\hline ChinPea [9] & 48 & 66.8 & 19 & 0 & 120 & 35 \\
\hline Hoh [10] & 24 & 59 & 13 & - & - & - \\
\hline Dimar [11] & 42 & 60 & 29 & 2 & 14.4 & 1 \\
\hline Dragsted [12] & 65 & 60 & 45 & 6 & 384 & 46 \\
\hline Kim [13] & 355 & 60 & 211 & 83 & - & 355 \\
\hline Elsaid [14] & 19 & 43.8 & 12 & 0 & 11.7 & 15 \\
\hline Erick [15] & 110 & 60 & 67 & 12 & 39 & - \\
\hline Gupta [3] & 260 & 67 & 163 & 0 & 32 & 158 \\
\hline Hadj- pavlou [16] & 101 & 46 & 76 & 0 & - & 39 \\
\hline Heyde [17] & 20 & 59.7 & 9 & 3 & 90 & 12 \\
\hline Karadimas [18] & 163 & 56 & 101 & 141 & 48 & - \\
\hline Lee [19] & 51 & 60 & 32 & 17 & - & 28 \\
\hline Livorsi [20] & 35 & 53 & 30 & 13 & - & 26 \\
\hline Martin Mc. [21] & 253 & 60 & 160 & 20 & 54 & 43 \\
\hline Masuda [22] & 5 & 63.8 & 2 & 0 & 62 & 2 \\
\hline Matsubara [23] & 52 & 70 & 31 & 0 & - & 30 \\
\hline Mavro-genis [24] & 153 & 57 & 93 & 3 & - & - \\
\hline Nolla [25] & 64 & 59 & 36 & 3 & 48 & 39 \\
\hline Ozkan [26] & 21 & 65 & 12 & 1 & - & - \\
\hline Robach [27] & 135 & 59 & 85 & 0 & - & 46 \\
\hline Rosinsky [28] & 16 & 68 & 9 & 2 & 10 & 2 \\
\hline Schinkel [29] & 32 & 61 & 18 & 5 & 44 & 19 \\
\hline Schuster [30] & 47 & 49 & 33 & 12 & - & 33 \\
\hline Shiban 1 [31] & 113 & 65 & 78 & 28 & - & 33 \\
\hline Shiban 2 [32] & 25 & 66 & 14 & 0 & - & 11 \\
\hline Shousha [33] & 30 & 64.5 & 19 & 11 & - & 24 \\
\hline Siddiq [34] & 57 & 56 & 33 & 27 & - & 57 \\
\hline Sobottke [35] & 32 & 74.9 & 21 & 12 & 65 & 12 \\
\hline Curry [36] & 48 & 61 & 30 & 1 & 7 & 48 \\
\hline Urrutia [37] & 102 & 65 & 74 & 34 & - & 11 \\
\hline
\end{tabular}




\begin{tabular}{|l|l|l|l|l|l|l|}
\hline Valacius [38] & 196 & 59 & 106 & 12 & 52 & 60 \\
\hline Woergen [39] & 62 & 64 & 35 & 14 & - & 8 \\
\hline Yoshimoto [40] & 45 & 65 & - & 2 & - & - \\
\hline Zarrouk [41] & 29 & 58 & - & 4 & 29 & 19 \\
\hline Dennis [42] & 84 & 62 & 49 & 47 & - & - \\
\hline
\end{tabular}

Table 2: International Standards for Neurological Classification of Spinal Cord Injury ASIA (ISNCSCI)**.

\section{A = Complete}

There is no motor function or sensation preserved in sacral segments S4-5.

\section{B = Sensory Incomplete}

Sensory but not motor function is preserved below the neurological level and includes the sacral segments S4-5 (light touch or pin prick at S4-5 or deep anal pressure) AND no motor function is preserved more than three levels below the motor level on either side of the body.

\section{C $=$ Motor Incomplete}

Motor function is preserved below the neurological level and more than half of the key muscles below the NLI have a muscle grade less than $3^{*}$.

\section{D = Motor Incomplete}

Motor function is preserved below the neurological level and at least half of the key muscle functions below the NLI have a muscle grade of at least 3 or higher*.

\section{$E=$ Normal}

Once sensation and motor function are graded as normal in all segments in a person with prior deficits, they are given an AISA of $\mathrm{E}$. A person without an initial $\mathrm{SCl}$ does not receive an AISA grade.

*It is important to recognize that for a patient with a grade of $\mathrm{C}$ or $\mathrm{D}$, they must either have voluntary anal contraction or sacral sensory sparing with sparing of motor function more than three levels below the motor level for that side of the body;

"Certain clinical pearls when using ISNCSCI include the followings:

- $\quad$ Both key and non-key muscle functions can be used to determine motor incomplete status (differentiation between AISA B from C).

- When distinguishing between a sensory incomplete versus a motor incomplete (AISA B from C) injury, the MOTOR LEVEL on each side is used. When distinguishing between motor incomplete injuries (AISA C from D), the SINGLE NEUROLOGICAL LEVEL is used. (Reference for the ASIA score)

\section{Study selection criteria}

The inclusion criteria were: 1) Studies on pyogenic spondylodiscitis; 2) Adult patients with confirmed spondylodiscitis who had been treated conservatively or surgically; 3) The series with objective neurologic exam before and after an appropriate treatment; and 4) Studies published in English. Non-pyogenic spondylodiscitis, animal studies, iatrogenic infections and the articles lacking specific description of neurologic findings were excluded.

\section{Data extraction}

The extracted data from each study consisted of number of patients, mean age, gender distribution, location of involved levels, period before appropriate treatment was instituted, presence of epidural abscess, neurologic status at presentation and at final follow up.

\section{Data analysis}

Data collection and analysis were performed using Microsoft Excel ${ }^{\circledast} 2010$ and the statistical software was used. Data distribution was assessed and continuous variables were compared using unpaired $\mathrm{t}$ test, Wilcoxon rank sum test. A p value $<0.05$ was considered statistically significant. To assess the correlations, the Fischer exact test was used. The neurologic outcome of the medically treated patients was compared with surgical group. Pooling of data within the subgroups was done using weighted averages based on the sample size.

\section{Classification of neurologic manifestations and sequelae}

The neurologic status and sequelae was expressed by various statements in the different articles. However, the most common applied classification for neurologic deficits was Frankel grading, which is similar to international standards for neurological classification of spinal cord injury (ISNCSCI) designed by the American Spinal Injury Associtation (ASIA) (Table 2).

We proposed certain equivalents for the Frankel grading in order to classify the reported neurologic status. Conditions described as "severe or marked", "paraplegic or tetraplegic or quadriplegic", "paralysis", 
"complete cord", "myelopathy" and "cauda equina" were considered equivalent to Frankel grade A and B. The reported physical exams did not allow to easily distinguish between Grade A and Grade B. The neurologic manifestation described as "moderate", "paresis", "foot drop" and "incomplete cord" were considered equal to Frankel grade C. Reported symptoms such as "mild", "minimal" and "weakness" were considered equal to Frankel grade D. The "pure sensory problems", "only numbness", "radicular pain" and "sciatalgia" were classified as equal to Frankel grade E. The neurologic results of treatment, medically or surgically, were classified as complete recovery (regain normal sensory and motor functions), partial recovery (one or two grade improvement in the motor functions), unchanged or deterioration (worsening of neurologic status).

\section{Results}

\section{Study characteristics and limitation}

As almost all the articles assessed neurologic outcomes retrospectively, the bias and limitation associated with retrospective analysis are also present in this study.

\section{Demographic data}

3236 patients with pyogenic spondylodiscitis were included with a mean age 60.3 years. There were 1,966 males (62\%) out of 3,162 reporting gender data. There was a mean treatment delay of 56.24 days in 1828 cases with onset of symptoms prior to treatment initiation.

In addition, there was multi-level involvement in $513(16 \%)$ of 3212 patients. The most common location of vertebral infection was lumbar and thoracolumbar spine $(60 \%)$, followed by thoracic spine $(27 \%)$, and then cervical spine (13\%). The incidence of concomitant epidural abscess in the patients with neurologic deficit was $53 \%$ (1228 in 2331). The articles studying only cervical spondylodiscitis demonstrated higher risk of neurologic symptoms (52\%, 37 of 71 cases) and a higher frequency of epidural abscess formation (72\%, 36 of 50 cases) in comparison to the non-cervical involvement.

\section{Neurologic manifestations and sequelae (Table 3)}

Among 3236 spondylodiscitis cases, 1314 patients had a variety of neurologic manifestation: 415 (32\%) presented with subjective symptoms including radicular pain, sciatica or numbness, whereas 899 cases (68\%) had a significant neurologic deficit defined as Frankel $A, B, C$ or $D$.
Although the Frankel A \& B, the most severe subtypes of neurologic deficits, constituted a smaller group (22\%) of patients, they showed the lowest possibility for complete recovery $(16 \%, p<0.001)$ in addition to the highest risk to remain unchanged after treatment (34\%).

The majority of Frankel $C(N=333)$ had partial recovery (53\%) whereas $29 \%$ had complete recovery. A remarkable number of Frankel $D(N=280)$ exhibited complete recovery (53\%) with almost an equal number of patients had partial $(25 \%)$ or no recovery $(20 \%)$. Approximately $34 \%$ of patients with neurologic symptoms ( $n=449$ ) promptly underwent surgery after confirmation of diagnosis. Whereas, 353 patients (27\%) sustained surgical intervention between 1-14 months after diagnosis.

We compared the outcome of neurologic impairment in the patients who were treated non-surgically $(n=97)$ with the patients who underwent surgical procedure initially $(n=449)$. Surgical intervention was associated with a higher rate of neurologic recovery $(R=-0.205, p$ $<0.000)$.

\section{Discussion}

The current study highlights the relatively poor prognosis of neurologic deficits associated with pyogenic spondylodiscitis. Delays in diagnosis and treatment can lead to progressive infection that spreads into the spinal canal resulting in epidural abscess formation [43,44]. The compressive effects of epidural abscesses cause severe pain in addition to myelopathy and radiculopathy [45]. In addition, associated ischemia and infarction of the spinal cord can aggravate the neurological status. Furthermore, vertebral bone destruction and secondary spinal instability potentially exacerbates canal compromise beside neurologic compression [46].

The rate of neurologic compromise has been reported from $7 \%$ by Hadjipavlou up to $57 \%$ by Curry Jr, et al. At least a simple extremity weakness manifests in $79 \%$ of patients with neurologic impairment, according to Butler study $[8,16,36,47]$. Aneta, et al. reported neurological symptoms in $1 / 3$ of the cases and ranged from radicular pain to radicu lopathy $(29 \%)$ to paresis $(2-13 \%)$ and cauda equina syndrome. (10\%) [48]. Current systematic review demonstrated radicular pain and absence of motor deficit in $32 \%$ of patients with neurologic findings. However, significant motor deficits occurred in $68 \%$ of patients consisted of $22 \%$ Frankel $A$ \& B, 25\% Frankel C and 21\% Frankel D.

Table 3: Neurologic recovery stratified by Frankel Grade.

\begin{tabular}{|l|l|l|l|l|l|}
\hline & Complete recovery & Partial recovery & Unchanged & Deteriorated & Total \\
\hline Frankel A\&B & $45(16 \%)$ & $137(48 \%)$ & $98(34 \%)$ & $6(2 \%)$ & $286(22 \%)$ \\
\hline Frankel C & $97(29 \%)$ & $178(53 \%)$ & $53(16 \%)$ & $5(2 \%)$ & $333(25 \%)$ \\
\hline Frankel D & $149(53 \%)$ & $71(25 \%)$ & $55(20 \%)$ & $5(2 \%)$ & $280(21 \%)$ \\
\hline Total & $291(32 \%)$ & $386(43 \%)$ & $206(23 \%)$ & $16(2 \%)$ & 899 \\
\hline
\end{tabular}


The relatively high percentage of Frankel A \& B case that were paraplegic or had a cauda equina syndrome might be attributed to the age, delayed diagnosis, epidural abscess formation, multi-level involvement, or cord level involvement. The roles of these factors in development of neurologic impairment were assessed:

1) Age: In the past decades, the most frequently affected people were elderly patients who more often experience multiple co-morbidities and are subject to drug-resistant organisms, particularly MRSA [45]. However, the current study demonstrated a drift of neurologic symptoms to the younger ages (range: 43-70 years, median: 60.3 years), that is high likely attributed to the increased number of IV drug user patients

2) Delayed diagnosis: The delayed diagnosis of spondylodiscitis, reported between 1 and 6 months, has significant impact on the natural history and the neurological outcome This systematic review confirmed the high possibility of delayed diagnosis in the spondylodiscitis patients with neurologic deficit, roughly 56.2 days (from 10 to 120 days). The diffuse and non-specific back pain, commonly absence of constitutional symptoms, inconclusive or late responding lab tests, late appearance of radiographic features, and general tendency to attribute the back pain to the degenerative changes particularly in older patients, all lead to delayed diagnosis. Delayed treatment often facilitates the "break out" of the infection into the adjacent tissues planes including the epidural space, the psoas muscles, paraaortic/retroperitoneally in the abdomen, retropharyngeally in the neck, and paravertebral and retroplural in the chest along with the development of sepsis. The infection spreads from the disc space into any available space which explains the frequency of epidural abscess formation in the patients with spondylodiscitis. Another important consequence of the delay in diagnosis of spondylodiscitis is the progresson of bony destruction that leads to progressive destruction of the endplates, the trabecular bone of the vertebra and progressive collapse and segmental kyphosis leading to instability $[47,48]$.

3) Epidural abscesses formation: It has been commonly reported in the patients with significant neurologic deficits, leading to myelopathy, radiculopathy or back pain. In this systematic review, the epidural abscess was found in $56 \%$ of spondylodiscitis cases with neurologic symptoms. The frequency of the development of epidural abscesses may in fact be the primary cause of the frequently encountered neurologic symptoms encountered with spondylodiscitis [16].
4) Multi-level involvement: The most common location of vertebral osteomyelitis has been reported in the lumbar, then thoracic, and then cervical area, respectively. Multi-level involvement has been reported in $3-13 \%$ of patients $[16,49]$. We found the distribution of spinal infection resembling the previous studies and the likelihood of multilevel involvement was approximately $16 \%$. Presumably, multiple episodes of sepsis particularly in IV drug users can explain the frequency of multilevel spondylodiscitis associated with neurologic involvement.

5) Cord level involvement: This review supports a higher level of risk of a neurological deficit when the spondylodiscitis involves the cervical or thoracic spine The presence of a spondylodiscitis infection in the cervical spine is relatively uncommon but the severity of neurologic compromise and the incidence of concomitant epidural abscess is higher than thoracic or lumbar involvement [33]. This study also confirmed neurologic deficit in $52 \%$ and epidural abscess in $72 \%$ of cervical spondylodiscitis cases.

Conventional treatment of spondylodiscitis is consisted of administration of appropriate antibiotics for 6-12 weeks and surgical intervention in the circumstances with failure of conservative treatment $[43,47,50]$. However, great diligence must be maintained during conservative treatment since rapid progression of bony destruction, instability, segmental kyphosis, and a neurologica deficient will demand abandoning antibiotic therapy alone and require surgical debridement. Neurologic compromise has led to several authors suggesting different treatments. Yoshimoto, et al. evaluated the result of conservative treatment in paralysed patients who were not able to undergo surgery due to poor general condition. He discovered that paralysis improved in $73 \%$ of these patients with nonoperative treatment [40]. Cheung, et al. believe that only $10-20 \%$ of patients suffering from pyogenic spondylitis require open surgery. He also expressed that surgical decompression can improve the prognosis for neurological recovery much better than non-operative management [51]. Graeff, et al. pointed out that epidural abscess, multilevel osteomyelitis, or diabetes escalate the risk of conservative treatment failure [52] McHenry MC, concluded that in the patients with neurologic compromise, the outcome of surgery was favorable in nearly $70 \%$; even better results was achieved in the absence of diagnostic delay [21]. Zarghooni, et.al reported persisted motor deficit in 30\% and hypaesthesia in $90 \%$ after surgical intervention but the quality of life and patients' satisfaction was higher in the surgical treated group of patients. Lerner, et al. identified an improvement of neurological deficits 
for $76 \%$ after surgery while $20 \%$ showed no change [53]. Hadjipavlou, et al. demonstrated that only $23 \%$ of patients with paralysis on admission recovered completely after surgical decompression [16].

In contrast to the previous authors, we compared the frequency and outcome of different Frankel's grades. Approximately $27 \%$ of conservatively treated deficits experienced failure of treatment and underwent surgical approach from 1 to 14 months after diagnosis. Furthermore, $34 \%$ of patients with neurologic symptoms required prompt surgery because of severe (Frankel $A$ or B) or progressive neurologic impairment.

\section{Conclusion}

Due to remarkable number of severe neurologic deficits in addition to their poor recovery even after surgical intervention, it is crucial to establish diagnosis of pyogenic spondylodiscitis in a timely manner. Surgical treatment, per formed in an appropriate time, high likely is associated with a higher neurologic recovery rate in pyogenic spondylodiscitis.

\section{References}

1. Jensen AG, Espersen F, Skinhoj P, Rosdah VT, FrimodtMoller N (1997) Increasing frequency of vertebral osteomyelitis following Staphylococcus aureus bacteraemia in Denmark 1980-1990. J Infect 34: 113-118.

2. Duarte RM, Vaccaro AR (2013) Spinal infection: State of the art and management algorithm. Eur Spine J 22: 27872799.

3. Gupta A, Kowalski TJ, Osmon DR, Enzler M, Steckelberg JM, et al. (2014) Long-Term outcome of pyogenic vertebral osteomyelitis: A Cohort Study of 260 Patients. Open Forum Infect Dis 1: ofu107.

4. Shunji-Asamoto $T$, Doi $H$, Endoh $T$, Ida $M$, Sakagawa $H$, et al. (2005) Spondylodiscitis: Diagnosis and treatment. Surgical Neurology 64: 103-108.

5. Ascione T, Balato G, Di Donato SL, Pagliano P, Granata F (2017) Clinical and microbiological outcomes in haematogenous spondylodiscitis treated conservatively. Eur Spine J 26: 489-495.

6. Bernard L, Dinh A, Ghout I, Simo D, Zeller V, et al. (2015) Antibiotic treatment for 6 weeks versus 12 weeks in patients with pyogenic vertebral osteomyelitis: An open-label, noninferiority, randomized, controlled trial. Lancet 385: 875882.

7. Bettini N, Girardo M, Dema E, Cervellati S (2009) Evaluation of conservative treatment of non specific Spondylodiscitis. Eur Spine J 18: S143-S150.

8. Cervan AM, de Dios Colmenero J, Del Arco A, Villanueva F, Guerado E (2012) Spondylodiscitis in patients under haemodyalisis. Int Orthop 36: 421-426.

9. Lin C-P, Li Ma H-L, Wang S-T, Liu C-L, Yu W-K, et al. (2012) Surgical results of long posterior fixation with short fusion in the treatment of pyogenic spondylodiscitis of the thoracic and lumbar spine. Spine 37: E1572-E1579.

10. Hoh DJ, Wang MY (2011) Infections of the Thoracic Spine. In The comprehensive treatment of the aging spine. Elsevier Inc 301-311.
11. Dimar JR, Carreon LH, Glassman SD, Campbell MJ, Hartman MJ, et al. (2004) Treatment of pyogenic vertebral osteomyelitis with anterior debridement and fusion followed by delayed posterior spinal fusion. Spine 29: 326-332.

12. Dragsted C, Aagaard T, Ohrt-Nissen S, Gehrchen M, Dah B (2017) Mortality and health-related quality of life in patients surgically treated for spondylodiscitis. J Orthop Surgery 25.

13. Kim SD, Melikian R, Ju KL, Zurakowski D, Wood KB, et al. (2014) Independent predictors of failure of nonoperative management of spinal epidural abscesses. Spine $\mathrm{J} 14$ : 1673-1679.

14. Elsaid A, Makhlouf M (2015) Surgical management of spontaneous pyogenic spondylodiscitis: Clinical and radiological outcome. Egyptian J Neurosurgery 30: 221226.

15. Legrand E, Flipo RM, Guggenbuhl P, Masson C, Maillefert JF, et al. (2001) Management of nontuberculous infectious discitis. Treatments used in 110 patients admitted to 12 teaching hospitals in France. Joint Bone Spine 68: 504-509.

16. Hadjipavlou AG, Mader JT, Necessary JT, Muffoletto AJ (2000) Hematogenous pyogenic spinal infections and their surgical management. Spine 25: 1668-1679.

17. Heyde CE, Boehm H, El Saghir H, Tschoke SK, Kayser R (2006) Surgical treatment of spondylodiscitis in the cervical spine: Aminimum 2-year follow-up. Eur Spine J 15: 13801387.

18. Karadimas EJ, Bunger C, Lindblad BE, Hansen ES, Hoy K, et al. (2008) Spondylodiscitis. A retrospective study of 163 patients. Acta Orthop 79: 650-659.

19. Lee Y, Kim BJ, Kim SH, Lee SH, Hyung W, et al. (2018) Comparative analysis of spontaneous infectious spondylitis: Pyogenic versus tuberculous. J Korean Neurosurg Soc 61: 81-88.

20. Livorsi DJ, Daver NG, Atmar RL, Shelburnea SA, White C $\mathrm{Jr}$, et al. (2008) Outcomes of treatment for hematogenous Staphylococcus aureus vertebral osteomyelitis in the MRSA ERA. J Infect 57: 128-131.

21. McHenry MC, Easly KA, Locker GA (2002) Vertebral osteomyelitis: Long-term outcome for 253 patients from 7 Cleveland-area hospitals. Clin Infect Dis 34: 1342-1350.

22. Masuda T, Miyamoto K, Hosoe H, Sakaeda H, Tanaka M, et al. (2006) Surgical treatment with spinal instrumentation for pyogenic spondylodiscitis due to methicillin-resistant Staphylococcus aureus (MRSA): A report of five cases. Arch Orthop Trauma Surg 126: 339-345.

23. Matsubara T, Yamada K, Sato K, Gotoh M, Nagata K, et al. (2018) Clinical outcomes of percutaneous suction aspiration and drainage for the treatment of infective spondylodiscitis with paravertebral or epidural abscess. Spine J 18: 15581569.

24. Mavrogenis AF, Igoumenou V, Tsiavos K, Megaloikonomos P, Panagopoulos GN, et al. (2016) When and how to operate on spondylodiscitis: A report of 13 patients. Eur J Orthop Surg Traumatol 26: 31-40.

25. Nolla JM, Ariza J, Gómez-Vaquero C, Fiter J, Bermejo J, et al. (2002) Spontaneous pyogenic vertebral osteomyelitis in nondrug users. Semin Arthritis Rheum 31: 271-278.

26. Özkan N, Wrede K, Ardeshiri A, Hagel V, Dammann P, et al. (2014) Cervical spondylodiscitis- A clinical analysis of surgically treated patients and review of the literature. Clinical Neurology and Neurosurgery 117: 86-92.

27. Robbach BP, Niethammer TR, Paulus AC, Melcher C, 
Birkenmaier C, et al. (2014) Surgical treatment of patients with spondylodiscitis and neurological deficits caused by spinal epidural abscess (SEA) is a predictor of clinical outcome. J Spinal Disord Tech 27: 395-400.

28. Rosinsky P, Mandler S, Netzer N, Ady M, Elmaliache D, et al. (2018) Antibiotic-resistant spondylodiscitis with canal invasion and aggressive evolution to epidural abscess: A case series of spontaneous occurrence in 16 Patients. Int $J$ Spine Surg 12: 743-750.

29. Schinkel C, Gottwald M, Andress H-J (2003) Surgical treatment of spondylodiscitis. Surg Infect 4: 387-391.

30. Schuster JM, Anthony M, Avellino Frederick A Mann, Girouard AA, et al. (2000) Use of structural allografts in spinal osteomyelitis: A review of 47 cases. J Neurosurg Spine 93: 8-14.

31. Shiban E, Janssen I, Wostrack M, Krieg SM, Ringel F, et al. (2014) A retrospective study of 113 consecutive cases of surgically treated spondylodiscitis patients. A single-center experience. Acta Neurochir 156: 1189-1196.

32. Shiban E, Janssen I, Wostrack M, Krieg SM, Horanin M, et al. (2014) Spondylodiscitis by drug-multiresistant bacteria: A single-center experience of 25 cases. Spine J 14: 28262834.

33. Shousha M, Boehm H (2012) Surgical treatment of cervical spondylodiscitis. A review of 30 consecutive Patients. Spine 37: E30-E36.

34. Siddiq F, Chowfin A, Tight R, Sahmoun AE, Smego RA Jr (2004) Medical vs surgical management of spinal epidural abscess. Arch Intern Med 164: 2409-2412.

35. Sobottke R, Röllinghoff M, Zarghooni K, Zarghooni K, Schluter-Brust K, et al. (2010) Spondylodiscitis in the elderly patient: Clinical mid-term results and quality of life. Arch Orthop Trauma Surg 130: 1083-1091.

36. Curry WT Jr, Hoh BL, Amin-Hanjani S, Eskandar EN (2005) Spinal epidural abscess: Clinical presentation, management, and outcome. Surg Neurol 63: 364-371.

37. Urrutia J, Campos M, Zamora T, Canessa V, Garcia P, et al. (2013) Doe's pathogen identification influence clinical outcomes in patients with pyogenic spinal infections? J Spinal Disord Tech 28: E417-E421.

38. Valancius K, Hansen ES, Høy K, Helmig P, Niedermann B, et al. (2013) Failure modes in conservative and surgical management of infectious spondylodiscitis. Eur Spine J 22: 1837-1844.

39. Woertgen C, Rothoerl RD, Englert C, Neumann C (2006) Pyogenic spinal infections and outcome according to the 36 -item short form health survey. J Neurosurg Spine 4: 441-446.
40. Yoshimoto M, Takebayashi T, Kawaguchi S, Tsuda H, Ida $\mathrm{K}$, et al. (2011) Pyogenic spondylitis in the elderly: A report from Japan with the most aging society. Eur Spine J 20: 649-654.

41. Zarrouk V, Feydy A, Sallés F, Dufour V, Guigui $P$, et al. (2007) Imaging does not predict the clinical outcome of bacterial vertebral osteomyelitis. Rheumatology 46: 292295.

42. Dennis Hey HW, Nathaniel Ng LW, Tan CS, Fisher D, Vasudevan A, et al. (2017) Spinal implants can be inserted in patients with deep spine infection-results from a large cohort study. Spine (Phila Pa 1976) 42: E490-E495.

43. Herren $C$, Jung N, Pishnamaz M, Breuninger $M$, Siewe $J$, et al. (2017) Spondylodiscitis: Diagnosis and treatment options. A systematic review. Dtsch Arztebl Int 11: 875-882.

44. Cornett CA, Vincent SA, Crow J, Hewlett A (2016) Bacterial spine infections in adults: Evaluation and management. $J$ Am Acad Orthop Surge 24: 11-18.

45. Fantoni M, Trecarichi EM, Rossi B, Mazzotta V, Di Giacomo $G$, et al. (2012) Epidemiological and clinical features of pyogenic spondylodiscitis. Eur Rev Med Pharmacol Sci 16: 2-7.

46. Babinchak TJ, Riley DK, Rotheram EB Jr (1997) Pyogenic vertebral osteomyelitis of the posterior elements. Clin Infect Dis 25: 221-224.

47. Butler JS, Shelly MJ, Timlin M, Powderly WG, O'Byrne JM (2006) Non tuberculous pyogenic spinal infection in adults: A 12-year experience from a tertiary referral center. Spine 31: 2695-2700.

48. Petkova AS, Zhelyazkov CB, Kitov BD (2017) Spontaneous Spondylodiscitis - Epidemiology, Clinical Features, Diagnosis and Treatment. Folia Med (Plovdiv) 59: 254-260.

49. Mylona E, Samarkos M, Kakalou E, Fanourgiakis $P$, Skoutelis A (2009) Pyogenic vertebral osteomyelitis: A systematic review of clinical characteristics. Semin Arthritis Rheum 39: 10-17.

50. Aljawadia A, Jahangira N, Jeelani A, Ferguson Z, Niazi $\mathrm{N}$, et al. (2019) Management of pyogenic spinal infection, review of literature. J Orthop 16: 508-512.

51. Cheung WY, Luk KDK (2012) Pyogenic spondylitis. Int Orthop 36: 397-404.

52. Graeff JJ, Pereira NR, van Wulfften Palthe OD, Nelson SB, Schwab JH (2017) Prognostic factors for failure of antibiotic treatment in patients with osteomyelitis of the spine. Spine (Phila Pa 1976) 42: 1339-1346.

53. Zarghooni K, Röllinghoff M, Sobottke R, Eysel P (2012) Treatment of spondylodiscitis. Int Orthop 36: 405-411. 